questionnaire was sent to all ACPRC members and circulated to members of the Chartered Society of Physiotherapy, with a request for a response from each institution, providing information on the number of respiratory physiotherapists, their grading and the estimated percentages of various diagnostic respiratory cases seen on a daily basis. 149 responses were received: $70 \%(n=105)$ from acute trusts, $24 \%(n=36)$ from primary care organisations. 73\% $(n=110)$ of respiratory physiotherapists were employed by physiotherapy departments: $59 \%(n=89)$ as dedicated medical respiratory physiotherapy teams, the rest providing cross speciality respiratory physiotherapy cover. The results highlight the model of staffing most often seen in respiratory physiotherapy, with the team consisting of a range of staffing grades but no standard team structure nationally. The level of physiotherapy clinician leading the team varied from Band 7 to a Consultant Respiratory Physiotherapist $(8 \mathrm{~A}-8 \mathrm{D})$ : the average was less than 1 at Band 8 nationally. $54 \%(n=81)$ of responders were ACPRC members, $19 \%$ $(n=28)$ both ACPRC and BTS members. The survey identified that largely the respiratory physiotherapy workforce is not embedded within respiratory medicine departments which means that appreciation of multidisciplinary team membership is of even greater importance. Despite the survey identifying a higher number of respiratory physiotherapists compared to earlier audit results, it also highlighted a workforce capacity shortfall, leaving some respiratory patients untreated on a daily basis. In addition, there is a need to encourage membership of special interest groups such as the ACPRC and BTS to promote exchange and dissemination of good practice.

Abstract P225 Table 1 Comparison of numbers of respiratory specialist physiotherapists nationally, identified by two audits

\begin{tabular}{llll}
\hline & & $\begin{array}{l}\text { ACPRC/BTS Physiotherapy (PT) } \\
\text { Survey 2009 (Mean WTE) }\end{array}$ \\
\cline { 3 - 4 } Profession & $\begin{array}{l}\text { 2008 National } \\
\text { (Median no WTE) }\end{array}$ & $\begin{array}{l}\text { Medical respiratory } \\
\text { PT team }\end{array}$ & $\begin{array}{l}\text { Cross speciality } \\
\text { respiratory PT team }\end{array}$ \\
\hline $\begin{array}{l}\text { Respiratory } \\
\text { Specialist }\end{array}$ & $1(0.5-2)$ & 3 qualified & 6.83 qualified \\
Physiotherapist & & 0.76 assistant & 1.62 assistant \\
\hline
\end{tabular}

\section{P226 PREVALENCE AND TREATMENT OF PAIN IN HOSPITAL IN-PATIENTS WITH RESPIRATORY DISEASE}

doi:10.1136/thx.2010.151068.27

K Matthews, D Brunnen, Y Mahmood, E H Baker. St George's, University of London, London, UK

Introduction and objectives Pain is common, with $43 \%$ of medical inpatients experiencing moderate to severe pain [Dix et al BJA 2004;92(2):235-237]. Factors contributing to inadequate pain relief include concerns about analgesic side effects, drug interactions and impact of treatment on co-morbidities. In respiratory in-patients we audited prevalence and severity of pain, adequacy of pain relief and contraindications to escalation of analgesia.

Methods Unselected adult inpatients ( $\geq 16$ years) with respiratory disease managed on a respiratory specialist ward were included in the audit. Patients with lung cancer or chest drains were excluded. Diagnoses, investigation results and medications were collected from patient records and patients underwent pain assessment (Brief Pain Inventory). Analgesia was defined as inadequate if patients reported an average pain score or pain interference score (pain interfering with daily activities) $>3 / 10$ during the previous $24 \mathrm{~h}$. For patients with inadequate analgesia, cautions and contraindications to analgesics and non-steroidal anti-inflammatory drugs (NSAIDs) were determined to establish whether analgesia could be escalated.
Results Of 101 patients interviewed, main respiratory diagnoses were: COPD (40\%), pneumonia/LRTI (38\%), asthma (13\%) and other (10\%). 52 patients reported any pain in the last $24 \mathrm{~h}$, of which the sites of worst pain were chest (44\%), back (25\%), limb (19\%) and other $(12 \%)$. Of these patients, $85 \%(n=44)$ were assessed as having inadequate analgesia. Abstract P226 Table 1 groups those patients with inadequate analgesia by position on the WHO analgesic ladder and details the proportion of patients who have no contraindication to stepping up the ladder. Abstract P226 Table 1 also highlights the proportion of patients who may benefit from adjuvant NSAID therapy. Of those patients with inadequate analgesia, $82 \%(n=36)$ had no contraindication to escalation of analgesia and $32 \% \quad(n=14)$ had no contraindication to treatment with NSAIDs.

Abstract P226 Table 1 Analgesic options for 44 patients with inadequate pain relief

\begin{tabular}{lcccll}
\hline & $\begin{array}{l}\text { No } \\
\text { analgesia }\end{array}$ & Paracetamol & $\begin{array}{l}\text { Mild/moderate } \\
\text { opioids }\end{array}$ & $\begin{array}{l}\text { Strong } \\
\text { opioids }\end{array}$ \\
\hline Step-up contraindicated & 0 & 3 & 0 & 5 & $18 \%$ \\
Step-up possible & 12 & 14 & 10 & 0 & $82 \%$ \\
NSAID contraindicated & 11 & 12 & 5 & 2 & $68 \%$ \\
NSAID possible & 1 & 5 & 5 & 3 & $32 \%$ \\
Total & 12 & 17 & 10 & 5 & \\
\hline
\end{tabular}

Conclusions Pain is common in hospital in-patients with respiratory disease. $44 \%$ of respiratory in-patients did not receive adequate analgesia. $82 \%$ of these had no contraindication to stepping up the pain ladder and $32 \%$ could have had an NSAID added to their treatment. Respiratory patients may benefit from closer assessment of their pain and options regarding prescribed analgesia.

\section{P227 DISPARITIES IN CARE OF ADULT CF PATIENTS IN THE UK}

doi:10.1136/thx.2010.151068.28

${ }^{1} \mathrm{M}$ Salako, ${ }^{2} \mathrm{~S} J$ MacNeill, ${ }^{3} \mathrm{E}$ Gunn, ${ }^{3} \mathrm{M}$ Baker, ${ }^{4} \mathrm{D}$ Bilton, ${ }^{2} \mathrm{P}$ Cullinan. ${ }^{1}$ Imperial College, London, UK; ${ }^{2}$ National Heart and Lung Institute (Imperial College), London, UK; ${ }^{3}$ Cystic Fibrosis Trust, Bromley, UK; ${ }^{4}$ Royal Brompton Hospital, London, UK

Background Studies in the late '80s and early '90s suggested that survival in UK CF patients was better in those from non-manual social classes and that adults attending specialist clinics $(66 \%$ of the total) received more intensive care. Twenty years on, we assessed whether treatments and outcomes varied by specialist care and the socio-economic status (SES) of patients.

Methods The CF Trust provided 2008 annual review data for patients attending UK adult clinics $(n=3182)$. Three models of care were identified: "centre", "shared" between specialist and nonspecialist clinics and non-specialist "stand-alone". SES was estimated by Townsend scores at CAS ward level. Distance to clinic was calculated as the distance between the patients' home postcode and that of their clinic.

Results In 2008 most patients received "centre care" (94\%) and few received "stand-alone care" (4\%). There were no differences in rates of dornase alfa, pancreatic enzyme or IV antibiotic treatment between models. The highest rates of chronic Pseudomonas aeruginosa (PA) infections were in patients attending "centre care" ("centre" 62\%: "shared" 56\%: "stand-alone" 49\%; $\mathrm{p}=0.01$ ) but there were no differences in $\mathrm{FEV}_{1} \%$ predicted. Most patients (91\%) lived $<50$ miles of their clinic; the distribution of clinics broadly reflected that of patients. Although those living near their clinic were less likely to be using dornase alfa ( $<50$ miles $43 \%$ : $\geq 50$ miles $52 \%$, $p=0.003$ ), there were no differences in chronic $\mathrm{Pa}$ infection or $\mathrm{FEV}_{1} \%$ predicted. There were more patients than expected in the least deprived 